\title{
POTENCIAL DE ENRAIZAMENTO DE MINIESTACAS DE Pinus Taeda L. PROVENIENTES DE BROTAÇÃO APICAL DE MUDAS JOVENS
}

\author{
Gisela Maria Pedrassani Andrejow ${ }^{1}$, Antonio Rioyei Higa ${ }^{2}$ \\ ${ }^{1}$ Mestranda em Ciências Florestais, UFPR, Curitiba, PR, Brasil - gisela.andrejow@ @rigesa.com.br \\ ${ }^{2}$ Eng. Florestal, Dr., Depto. de Ciências Florestais, UFPR, Curitiba, PR, Brasil - higa@ufpr.br \\ Recebido para publicação: 27/11/2007 - Aceito para publicação: 26/11/2008
}

\begin{abstract}
Resumo
O objetivo do presente trabalho foi avaliar o efeito do genótipo e do substrato no enraizamento de miniestacas provenientes de brotação apical de mudas de P. taeda com 90 dias de idade. O delineamento experimental foi de blocos casualizados em esquema fatorial 2 x 10: os substratos Plantmax ${ }^{\circledR}$ e Vermiculite ${ }^{\circledR}$ e dez diferentes genótipos, em quatro repetições cada, e parcelas de 114 miniestacas. A avaliação do percentual de enraizamento ocorreu aos 70 dias após o estaqueamento. Os resultados obtidos permitiram verificar que as brotações juvenis apresentaram alta capacidade de enraizar $(84,55 \%)$. A média de enraizamento de miniestacas no substrato Plantmax $®$ foi superior à de Vermiculite $囚$, sendo de $92,7 \%$ e $64,3 \%$, respectivamente. Não se observou diferença na porcentagem de enraizamento nas dez famílias de polinização aberta utilizadas no experimento, nas condições deste estudo.
\end{abstract}

Palavras-chave: Enraizamento; substrato; vermiculite.

\begin{abstract}
Rooting potentiality of Pinus taeda L. mini-cuttings collected from apical coppicing of young seedlings. This study aimed to evaluate the influence of the genotype (family) on the rooting potentiality of Pinus taeda L. mini-cuttings collected from apical coppicing of seedling with 90 days of age. The cuttings were distributed in a randomized blocks in a $2 \times 10$ factorial design. Two types of medium (Plantmax ${ }^{\circledR}$ and Vermiculite $\left.{ }^{\circledR}\right)$ were used in combination with ten different families. The 114 mini-cuttings plots were distributed into four blocks. Rootings were evaluated after 70 days. Based on the results, it was possible to verify that the young coppicing present high capacity of rooting (an average of $84.55 \%$ ) and no statistically significant differences were observed among the ten open pollination families in relation to the percentage of rooting Rooting using Plantmax® medium $(92.7 \%)$ was higher than rooting using Vermiculite ${ }^{\circledR}(64.3 \%)$ medium.
\end{abstract}

Keywords: Rooting; substrate; vermiculite.

\section{INTRODUÇÃO}

Pinus taeda L. é a espécie florestal mais plantada na região Sul do Brasil, com 609.683 ha reflorestados no Paraná e 350.823 ha em Santa Catarina (REMADE, 2005). O plantio anual chega à marca de 100 milhões de mudas, e o consumo de madeira roliça do gênero Pinus proveniente de plantações florestais para uso industrial no Brasil é de 33,2 milhões de $\mathrm{m}^{3}$ por ano. Os estados do Paraná e de Santa Catarina consomem 57\% desse total (NETO, 2002). Desse modo, devido a sua ampla utilização como matéria-prima, $P$. taeda tem sido uma das espécies florestais exóticas mais expressivas economicamente na região Sul do Brasil.

Ela é considerada uma das espécies de coníferas mais difíceis de propagar vegetativamente (HAMANN, 1995; ROCHA; NIELLA, 2002). A tecnologia de clonagem, via enraizamento de miniestacas, para implantação de reflorestamentos de $P$. taeda vem sendo explorada como um complemento à propagação de mudas. Assim, técnicas de propagação vegetativa adquirem relevância, 
com o objetivo de disponibilizar material genético selecionado, hoje escasso e caro (NIELLA; ROCHA, 2004).

Na Argentina, a experiência com estaquia em P. taeda é divulgada pela Florestal Bosques del Plata, que anuncia a produção de um milhão de mudas provenientes de propagação vegetativa. As cepas são originadas de sementes das melhores famílias de $P$. taeda, obtidas por meio de cruzamentos controlados e conduzidas em vasos, de onde são colhidas as estacas (PEZZUTTI, 2005). No Brasil, as primeiras tentativas de transferência da tecnologia de produção de mudas de eucalipto (microestaquia e hidrojardim clonal) para a clonagem de famílias de $P$. caribaea var. hondurensis e $P$. taeda foram realizadas e divulgadas pela International Paper (CAMPINHOS et al., 2000) e E. Furlan Consultoria, com propagação vegetativa para famílias de P. caribaea var. hondurensis (FURLAN, 2002). A utilização de sementes como fonte de propágulos resulta numa maior desuniformidade do material, o que é aceito pela dificuldade de obtenção de rejuvenescimento de material adulto em Pinus sp. (WEBER; STELZER, 2000).

Malavasi (1994) ressalta a importância significativa do genótipo na capacidade de enraizamento das estacas de coníferas, devido à existência de variações entre genótipos. Hamann (1995) observou diferença significativa no enraizamento das estacas de $P$. taeda para as diferentes famílias testadas.

A propagação de plantas por meio de estaquia depende de diversos fatores que influenciam no desenvolvimento e na diferenciação das raízes, tais como a juvenilidade dos brotos e ambiente de enraizamento (HARTMANN; KESTER, 1983; HIGASHI et al., 2000), a umidade, o substrato, a umidade relativa (UR) e a temperatura e luminosidade fornecidas às estacas durante o período de enraizamento (VALLE; CALDEIRA, 1978). Além disso, outros fatores, como a composição química e física do substrato e alguns estresses ambientais, podem também influenciar o enraizamento das estacas (HIGASHI et al., 2000).

O substrato usado em estaquia, em função do sistema de irrigação a ser empregado, deve ser constituído de material que propicie uma drenagem adequada, de forma a manter uma aeração satisfatória, evitando o apodrecimento da base das estacas (IKEMORI, 1975; VALLE; CALDEIRA, 1978). O uso de resíduos orgânicos florestais como componente de substratos para a produção de mudas é prática comum, sendo, de modo geral, a casca de Pinus o resíduo mais utilizado (MAIA, 1999). A vermiculite pura não se mostrou um substrato adequado para enraizamento de estacas de $P$. taeda, proporcionando melhor resultado quando misturada a outros substratos (CANCELA, et al., 2003). Rocha; Niella (2002) e Niella et al. (2003) recomendam casca de pinus compostada como substrato para estacas de P. taeda.

A formação de raízes em miniestacas de $P$. taeda é influenciada pela idade das mudas, de forma que o aumento no índice de enraizamento ocorre com a diminuição da idade das mudas, dificultando o enraizamento quando não se utiliza material juvenil dessa espécie como fonte de propágulos (ALCÂNTARA, 2005). Diaz-Sala et al. (1996) observaram que miniestacas de P. taeda originadas do hipocótilo de mudas de 50 dias apresentaram capacidade de regeneração de raízes sob circunstâncias indutivas maior do que aquelas oriundas do epicótilo.

Assim, este estudo teve como objetivo estudar o potencial de enraizamento de miniestacas originadas de brotações apicais de mudas jovens de dez famílias de $P$. taeda, usando-se dois tipos de substrato.

\section{MATERIAL E MÉTODOS}

O presente estudo foi realizado durante o ano de 2004, sendo conduzido na Divisão Florestal da Rigesa Celulose, Papel e Embalagens Ltda., localizada no município de Três Barras, Planalto Norte Catarinense, e situada a $26^{\circ} 07^{\prime} 41^{\prime \prime} \mathrm{S}$ e $50^{\circ} 19^{\prime} 30^{\prime \prime} \mathrm{O}$, numa altitude de $780 \mathrm{~m}$. A temperatura média anual é de $17{ }^{\circ} \mathrm{C}$, com ocorrência de geadas no inverno. A precipitação média anual é de $1200 \mathrm{~mm}$, e a umidade relativa do ar média anual é de $64 \%$.

O experimento foi conduzido em casa de vegetação com cobertura plástica e lateral em fibra de vidro, com exaustores de ar com sistema "pad fan", aquecimento por resistência elétrica e "fogger", automatizados por sensores de umidade e temperatura, sendo a temperatura interna média de $30{ }^{\circ} \mathrm{C}$ (variando de 10 a $32{ }^{\circ} \mathrm{C}$ ) e a umidade relativa do ar de $90 \%( \pm 5 \%)$.

Para este estudo, mudas de dez famílias de $P$. taeda (de 1 a 10), originadas de polinização aberta e selecionadas por produtividade, foram produzidas em tubetes plásticos de $56 \mathrm{~cm}^{3}$ de volume, com substrato comercial Plantmax ${ }^{\circledR}$. Muda e adubação com 150 g de Osmocote ${ }^{\circledR} 15-09-12$ por $^{3}$ de substrato. 
Quando essas mudas atingiram a idade de 90 dias, as brotações apicais com cinco $\mathrm{cm}$ de comprimento foram colhidas com o auxílio de tesoura e utilizadas como miniestacas, mantendo-se as acículas.

As miniestacas foram estaqueadas em substrato Plantmax estaca ${ }^{\circledR}$ e Vermiculite ${ }^{\circledR}$ fina. A composição e as características dos substratos são apresentadas na tabela 1. Após o estaqueamento, as miniestacas foram mantidas na casa de vegetação, recebendo irrigação por nebulização. A irrigação por nebulização foi mantida por três segundos, em intervalo de três minutos, por sete dias. Após esse período, passou a ser realizada somente durante o dia, por 15 dias. Após 21 dias, a irrigação foi realizada três vezes ao dia. Depois de 45 dias até a data de avaliação da porcentagem de enraizamento, a irrigação foi realizada sempre que necessário, de modo a manter a umidade do substrato, mas evitando sempre o seu encharcamento.

A avaliação do percentual de enraizamento das miniestacas para cada família ocorreu 70 dias após o estaqueamento, por meio da retirada das miniestacas do substrato.

O delineamento experimental utilizado nos experimentos foi de blocos casualizados em esquema fatorial 2 × 10, sendo os fatores substrato Plantmax ${ }^{\circledR}$ e Vermiculite ${ }^{\circledR}$, e famílias de 1 a 10 , com 114 miniestacas por parcela.

As variâncias foram inicialmente avaliadas quanto à sua homogeneidade pelo teste de Bartlett. Como as variáveis apresentaram variâncias heterogêneas, tiveram seus valores originais transformados por arco seno $\sqrt{x}$. As análises estatísticas foram realizadas com o programa estatístico MSTAT-C ${ }^{\circledR} 2.0$.

O modelo matemático utilizado para a análise de variância do experimento com substrato é apresentado pela Equação (1):

$$
\gamma_{i j}=\mu+\tau_{i}+v_{j}+\tau v_{i j}+\varepsilon_{i j}
$$

Em que: $\gamma_{i j} \quad=$ observação do i-ésimo tratamento na j-ésima parcela;

$\mu \quad=$ efeito constante (média geral);

$\tau_{i}=$ efeito do i-ésimo substrato (Plantmax ${ }^{\circledR}$ e Vermiculite $^{\circledR}$ );

$v_{j} \quad$ = efeito da j-ésima família (de 1 a 10);

$\tau v_{i j}=$ interação substrato versus família;

$\varepsilon_{i j} \quad=$ erro associado ao i-ésimo tratamento na j-ésima parcela.

Sob esse modelo, foram testadas as hipóteses:

$H_{0}:$ Plantmax $^{\circledR}=$ Vermiculite $^{\circledR}$

$H_{1}{\text { : } \text { Plantmax }^{\circledR} \text { difere de Vermiculite }}^{\circledR}$

Tabela 1. Composição e características químicas dos substratos Plantmax ${ }^{\circledR}$ e Vermiculite ${ }^{\circledR}$.

Table 1. Composition and chemical characteristics of the substrate Plantmax $^{\circledR}$ e Vermiculite ${ }^{\circledR}$.

\begin{tabular}{|c|c|c|c|c|c|c|c|c|c|c|c|c|}
\hline \multirow{2}{*}{ Substrato } & pH & Al & $\mathrm{Ca}^{+} \mathrm{Mg}$ & $\mathrm{H}^{+} \mathrm{Al}$ & $\mathbf{P}$ & $\mathbf{K}$ & \multirow{2}{*}{$\begin{array}{l}\text { M.O. } \\
\text { g/dm }\end{array}$} & SB & $\mathbf{t}$ & \multirow{2}{*}{$\frac{\mathbf{m}}{\%}$} & $\mathbf{T}$ & \multirow[t]{2}{*}{$\mathbf{V}$} \\
\hline & $\mathrm{H}_{2} \mathrm{O}$ & & Me/100cc & & \multicolumn{2}{|c|}{$\mathrm{mg} / \mathrm{l}$} & & & & & & \\
\hline Plantmax ${ }^{\circledR}$ & 5,7 & 1,11 & 31,4 & 6,4 & 1301,7 & 1870,0 & 2,37 & 36,2 & 37,3 & 2,97 & 42,6 & 85,1 \\
\hline Vermiculite $®$ & 6,4 & 0,29 & 9,8 & 0,8 & 47,0 & 490,0 & 1,84 & 11,0 & 11,3 & 2,56 & 11,8 & 93,6 \\
\hline
\end{tabular}

SB: soma de bases (me/100cc); t: CTC efetiva (me/100cc); m: saturação de Al; T: CTC a pH 7,0; V: saturação de bases.

\section{RESULTADOS E DISCUSSÃO}

O percentual de enraizamento, obtido para miniestacas provenientes de brotação apical de mudas jovens de famílias de $P$. taeda variou de $42,9 \%$ a $98,2 \%$, de acordo com a família e o substrato usado, conforme apresentado na tabela 2. 
Tabela 2. Enraizamento médio de miniestacas provenientes de broto apical de mudas de dez famílias de polinização aberta de $P$. taeda, avaliadas 70 dias após o estaqueamento em dois tipos de substrato (Plantmax ${ }^{\circledR}$ e Vermiculite ${ }^{\circledR}$ ).

Table 2. Medium root of the minicuttings deriving from apical coppicing of seedlings of ten pollination families open of P. taeda, evaluated 70 days after, in substrate Plantmax ${ }^{\circledR}$ and Vermiculite ${ }^{\circ}$.

\begin{tabular}{lccccccccccc}
\hline \multirow{2}{*}{ Substrato } & \multicolumn{10}{c}{ Família } & Média \\
\cline { 2 - 11 } & $\mathbf{1}$ & $\mathbf{2}$ & $\mathbf{3}$ & $\mathbf{4}$ & $\mathbf{5}$ & $\mathbf{6}$ & $\mathbf{7}$ & $\mathbf{8}$ & $\mathbf{9}$ & $\mathbf{1 0}$ & \\
\hline Plantmax $^{\circledR}$ & 94,0 & 93,9 & 94,5 & 92,7 & 90,9 & 98,2 & 96,2 & 82,5 & 91,3 & 90,3 & 92,7 a \\
Vermiculite $^{\circledR}$ & 74,0 & 77,1 & 64,2 & 62,7 & 56,8 & 42,9 & 63,5 & 68,4 & 54,3 & 87,1 & $64,3 \mathrm{~b}$ \\
Média da família & 84,4 & 85,2 & 79,4 & 77,9 & 72,0 & 71,4 & 79,4 & 74,9 & 73,1 & 87,5 & 78,5 \\
\hline
\end{tabular}

O tipo de substrato utilizado afetou a porcentagem de enraizamento das estacas. O resultado observado utilizando o substrato Plantmax ${ }^{\circledR}$ foi estatisticamente $(\mathrm{p}<0,05)$ superior ao obtido com o substrato Vermiculite ${ }^{\circledR}$ (Tabela 3).

Tabela 3. Análise de variância para porcentagem de enraizamento de miniestacas provenientes de broto apical de mudas de dez famílias de polinização aberta de $P$. taeda, avaliadas 70 dias após o estaqueamento em dois tipos de substratos (Plantmax ${ }^{\circledR}$ e Vermiculite $\left.{ }^{\circledR}\right)$.

Table 3. Variance analysis for percentage of root of the minicuttings deriving from apical coppicing of seedlings of ten pollination families open of $P$. taeda, evaluated 70 days after, in two types of substrate (Plantmax ${ }^{\circledR}$ e Vermiculite $\left.{ }^{\circledR}\right)$.

\begin{tabular}{lccc}
\hline Fator de variação & GL & QM & F calc \\
\hline Substrato & 1 & 3,501 & $58,627^{* *}$ \\
Família & 9 & 0,054 & $0,910^{\mathrm{ns}}$ \\
Substrato x Família & 9 & 0,086 & $1,444^{\mathrm{ns}}$ \\
Erro & 60 & 0,060 & \\
Total & 79 & & \\
Coeficiente de variação (\%) & 20,77 & & \\
* & \multicolumn{4}{c}{ significativos a 1\% de probabilidade; ns: não ignificativo. Dados transformados por arco seno $\sqrt{x}}$.
\end{tabular}

Semelhante ao observado por Cancela et al. (2003), a vermiculite não se mostrou um substrato adequado para enraizamento de estacas de $P$. taeda. Com ela pode-se obter melhores resultados quando misturada a outros substratos. Esses resultados melhores provavelmente devem-se ao fato do substrato Plantmax ${ }^{\circledR}$ ser formulado à base de casca de pinus compostada, material que propicia uma drenagem satisfatória, de forma a manter em equilíbrio as percentagens entre ar e água, evitando a morte dos tecidos da base das estacas. Um substrato para enraizamento deve oferecer suprimento de água adequado e uma boa relação umidade ar/água para indução e formação de raízes. Esses resultados concordam também com os de Maia (1999), em cuja pesquisa a mistura de casca de pinus compostada melhorou a porosidade e a aeração do substrato, sendo este um dos substratos mais utilizados. Resultados similares ao deste estudo, utilizando casca de pinus compostada como substrato para enraizamento de estacas de P. taeda, foram relatados por Rocha; Niella (2002) em testes para indução de enraizamento utilizando como substrato uma mistura de três partes de casca de pinus compostada para uma parte de perlita. Já Niella et al. (2003) recomendam casca de pinus compostada como substrato para enraizamento de estacas de $P$. taeda.

O substrato Plantmax ${ }^{\circledR}$ com $\mathrm{pH}$ de 5,7 resultou em melhor taxa de enraizamento quando comparado a Vermiculite ${ }^{\circledR}$ com pH de 6,4. Gruszynski (2002) afirma que o valor de pH do substrato pode afetar atividades fisiológicas, como o enraizamento, e que $\mathrm{pH}$ de 5,0 a 5,8 é o ideal para culturas em geral. Outra característica física do substrato que interfere no enraizamento é a CTC, que para Plantmax ${ }^{\circledR}$ é de 37,3 meq/100g e para Vermiculite ${ }^{\circledR}$ é de 11,3 meq/100g. Conforme Bataglia; Furlani (2004), que descrevem valores entre 75 a $150 \mathrm{meq} / 100 \mathrm{~g}$ como ideais para substratos, sendo aceitável valor superior a $20 \mathrm{meq} / 100 \mathrm{~g}$, o valor da CTC da vermiculite está abaixo do aceitável. Substratos com maior teor de matéria orgânica apresentam maior CTC.

Considerando as características químicas ( $\mathrm{CTC}$ e $\mathrm{pH})$ dos substratos testados, as médias de enraizamento de $98,2 \%$ (Plantmax ${ }^{\circledR}$ ) e $42,9 \%$ (Vermiculite $^{\circledR}$ ) e os resultados de Rocha; Niella (2002) e 
Niella et al. (2003), observa-se que o substrato mais indicado para enraizamento de miniestacas de $P$. taeda é o Plantmax ${ }^{\circledR}$.

A análise estatística (Tabela 3) revelou que o fator família e a interação substrato versus família não foram estatisticamente significativos $(p<0,05)$. Quando o substrato utilizado foi a Vermiculite ${ }^{\circledR}$, a média de enraizamento de todas as famílias foi de $64,3 \%$. Embora a interação substrato versus família não tenha apresentado valor significativo estatisticamente $(\mathrm{p}<0,05)$, na progênie 6 houve resposta muito distinta para os substratos testados, e na progênie 10 observou-se uma certa plasticidade em relação ao substrato (Figura 1).

Para o substrato Plantmax ${ }^{\circledR}$, as famílias testadas não diferiram estatisticamente $(\mathrm{p}<0,05)$. Furlan (2002) relatou que as porcentagens de enraizamento variaram entre famílias de $P$. caribaea var. hondurensis propagadas, com os melhores resultados superando 90\%. Hamann (1995) encontrou diferença significativa no enraizamento das estacas de $P$. taeda para as diferentes famílias testadas, resultado semelhante ao obtido para o substrato Vermiculite ${ }^{\circledR}$.

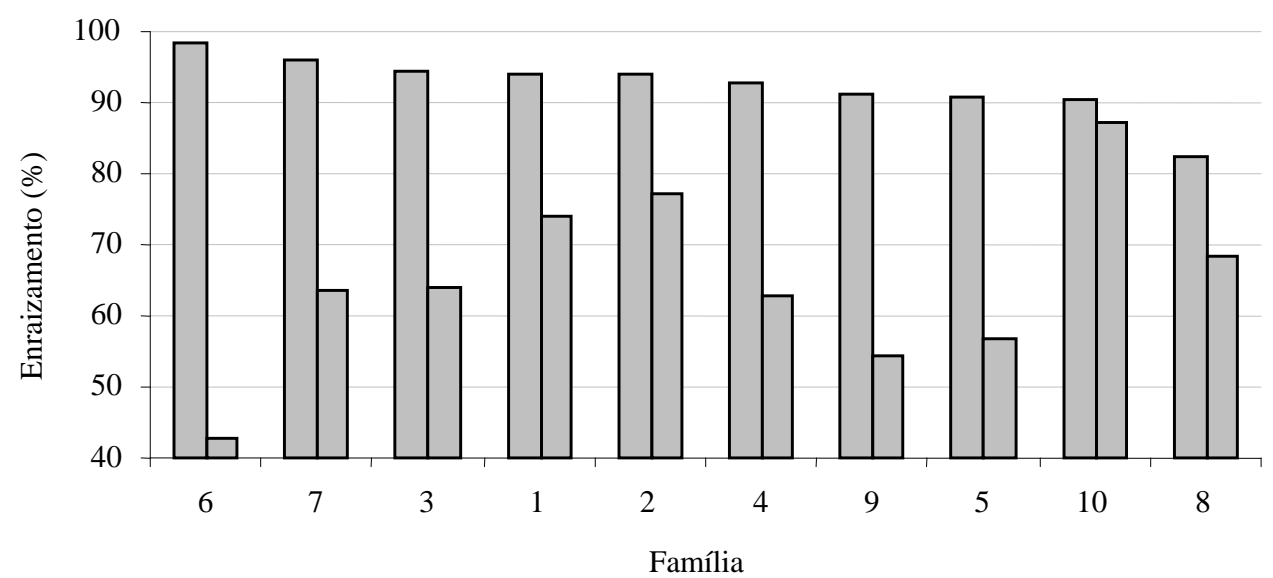

Figura 1. Porcentagem de enraizamento de miniestacas provenientes da coleta de brotação apical de mudas de dez famílias de polinização aberta de $P$. taeda, avaliadas aos 70 dias de cultivo em dois tipos de substrato (Plantmax ${ }^{\circledR}$ e Vermiculite ${ }^{\circledR}$ ).

Figure 1. Percentage of root of the minicuttings deriving from apical coppicing of seedlings of ten pollination families open of $P$. taeda, evaluated 70 days after, in two types of substrate (Plantmax ${ }^{\circledR}$ e Vermiculite ${ }^{\circledR}$ ).

Embora o gênero Pinus tenha sido considerado de difícil enraizamento, Wise; Caldwell (1992) relataram porcentagens de enraizamento de 0 a $60 \%$ para $P$. taeda e até $89 \%$ para $P$. elliottii var. elliottii $x$ $P$. caribaea var. hondurensis. Os experimentos conduzidos resultaram em porcentagem média de enraizamento de $78,5 \%$, sendo este valor superior ao obtido pelos autores citados anteriormente.

$\mathrm{O}$ resultado de enraizamento das brotações apicais utilizadas como miniestacas está de acordo com Diaz-Sala et al. (1996), que relatam que miniestacas de $P$. taeda originadas do hipocótilo retêm a capacidade de regenerar raízes quando originadas de mudas de 50 dias. Resultado similar foi observado por Alcântara (2005), que observou que miniestacas da mesma espécie coletadas de mudas mais jovens (60 dias de idade) apresentaram 85\% de enraizamento em comparação com 8,7\% quando as miniestacas foram colhidas de mudas de 150 dias de idade.

O presente estudo, utilizando brotações apicais de mudas de 90 dias de idade, de 10 famílias de $P$. taeda, comprovou a capacidade de enraizamento para $P$. taeda, quando as miniestacas são provenientes de material juvenil.

\section{CONCLUSÕES}

- Pode-se recomendar a utilização de material juvenil.de miniestacas de $P$. taeda para a produção de mudas.

- Para o enraizamento de miniestacas apicais de P. taeda, coletadas de mudas jovens, recomenda-se o uso do substrato Plantmax ${ }^{\circledR}$. 
- Para as dez famílias de $P$. taeda originadas de polinização aberta, os genótipos não interferiram na porcentagem de enraizamento das miniestacas utilizando substrato Plantmax ${ }^{\circledR}$.

- Os genótipos apresentaram porcentagem de enraizamento variável quando o substrato utilizado foi a Vermiculite ${ }^{\circledR}$.

\section{REFERÊNCIAS}

ALCANTARA, G. B. Miniestaquia de Pinus taeda. 64 f. Dissertação (Mestrado em Biologia) - Setor de Ciências Biológicas, Universidade Federal do Paraná, Curitiba, 2005.

BATAGLIA, O. C.; FURLANI, P. R. Nutrição mineral e adubação para cultivos em substratos com atividade química. In: BARBOSA, J. G. et al. Nutrição e Adubação de plantas cultivadas em substrato. Viçosa, MG: UFV, 2004. 434 p.

CAMPINHOS, E. N.; IANNELli, C. M.; CARDOSO, N. G.; AlMEIDA, M. A.; ROSA, A. C. Hidrojardim Clonal na Champion: uma otimização na produção de mudas de eucalipto. Revista Silvicultura, São Paulo, n. 80, p. 42-46, 2000.

CANCELA, K. C.; VIANA, J. J.; HIGA, A. R. Estaquia de Pinus taeda. 2003. Disponível em: 〈http://www.floresta.ufpr.br/fonlines/s11.htm>. Acesso em: 23/09/2005.

DIAZ-SALA, C.; HUTCHISON, K. W.; GOLDFARB, B.; GREENWOOD, M. S. Maturation-related loss in rooting competence by loblolly pine stem cuttings: the role of auxin transport, metabolism and tissue sensitivity. Physiologia Plantarum, Copenhagen, v. 97, n. 3, p. 481-490, 1996.

GRUSZYNSKI, C. Resíduo agro-industrial "Casca de Tungue" como componente de substrato para plantas. 99 p. Dissertação (Mestrado em Fitotecnia) - Faculdade de Agronomia, Universidade Federal do Rio Grande do Sul Porto Alegre, 2002.

HAMANN, A. Effects of hedging on maturation in loblolly pine: rooting capacity and root formation. Thesis (Máster of Science Degree) - State University of New York, New York. 1995. Disponível em: <http://genetics.forestry.ubc.ca/hamann/msthesis/msthesis.html>. Acesso em: 20/10/2004.

HARTMANN; H. T.; KeSTER, D. E. Plant Propagation: principles and practices. 4 ed. Englewood Cliffs: Pretice-Hall, 1983. 727 p.

HIGASHI, E. N.; SILVEIRA, R. L. V. A.; GONÇALVES, A. N. Evolução do jardim clonal de eucalipto para a produção de mudas. IPEF Notícias, Piracicaba, n. 24, v. 148, 2000.

IKEMORI, Y. M. Resultados preliminares sobre enraizamento de estacas de Eucalyptus spp. Informativo Técnico Aracruz, Aracruz, v. 1, 12 p., 1975.

MAIA, C. M. B. F. Uso da casca de Pinus e o lodo biológico como substrato para produção de mudas de Pinus taeda. Boletim de Pesquisa Florestal, Colombo, n. 39, 1999.

MALAVASI, U. C. Macropropagação vegetativa em coníferas: perspectivas biológicas e operacionais. Floresta e ambiente, ITAGUAI, RJ, n. 1, p. 131-135, 1994.

NETO C. M. Silvicultura . Revista da Madeira, Edição Especial Pinus, Curitiba, v. 12, n. 68, 2002.

NIELLA, F.; ROCHA, P.; PEZZUTTI, R.; SCHENONE, R. Manejo intensivo para la producción de estacas en plantas madres de Pinus taeda y Pinus elliottii x caribaea: efecto del tamaño de contenedor e intensidad lumínica. JORNADAS FORESTALES DE ENTRE RIOS, 18., 2003, Concordia. [Anales...]. Concordia: INTA y UNER, 2003.

Biotecnologias en desarrollo en la Facultad de Ciencias Forestales de la Universidad Nacional de Misiones-Argentina. Trabalho apresentado nas Jornadas de Mejoriamento Genético para Productores Forestales, Posadas, Misiones, Argentina. 15 e 16 de julho, 2004. p. 37-41.

PEZZUTTI, R. Território Florestal. 2005. Disponível em: <http://www.territoriodigital.com/notaTF.aspex?c=1503168710245580>. Acesso em: 14/03/2005. 
REMADE. Disponível em: <http://www.remade.com.br/banco_dados/silvicultura/5.php>. Acesso em 21/09/2005.

ROCHA, P.; NIELLA, F. Efecto de tratamientos inductivos en el enraizamento de estacas de Pinus elliottii x caribaea y P. taeda. Trabalho apresento na IX Jornadas Técnicas Forestales. INTA-FCF-ME y RNR y T - Eldorado, Missiones, Argentina, 2002.

VALLE, C. F.; CALDEIRA, C. J. Fatores que afetam o enraizamento de estacas de Eucalyptus spp. Boletim Informativo IPEF, Piracicaba, v. 6, n. 18, p. 107-117, 1978.

WEBER, J.; STELZER, H. Operational rooted cuttings in southern Pines. In: WESTERN FOREST AND CONSERVATION NURSERY ASSOCIATION CONFERENCE, 2000, Kailua-Kona. Proceedings... Kailua-Kona: Western Forest and Conservation Nursery Association, 2000. p. 91-92.

WISE, F.; CALDWELL, T. Macropropagation of conifers by stem cuttings. En: Proceedings of the Southern regional information Exchang Group Biennial Symposium on Forest genetics:Applications of Vegetative Propagation in Forestry. Huntsville: Southern Forest Experiment Station, 1992. p. 51-73. 